\title{
Investigations on Oil Flow Rates Projected on the Casing Walls by Splashed Lubricated Gears
}

\author{
G. Leprince, ${ }^{1,2}$ C. Changenet, ${ }^{1}$ F. Ville, ${ }^{2}$ and P. Velex ${ }^{2}$ \\ ${ }^{1}$ Laboratoire d'Energétique, Université de Lyon-ECAM Lyon, 40 Montée Saint-Barthélemy, 69321 Lyon Cedex 05, France \\ ${ }^{2}$ INSA de Lyon, Université de Lyon, LaMCoS, UMR CNRS 5259, Bâtiment Jean d'Alembert, 18-20 Rue des Sciences, \\ 69621 Villeurbanne Cedex, France
}

Correspondence should be addressed to P. Velex, philippe.velex@insa-lyon.fr

Received 26 June 2012; Accepted 19 October 2012

Academic Editor: Ahmet Kahraman

Copyright () 2012 G. Leprince et al. This is an open access article distributed under the Creative Commons Attribution License, which permits unrestricted use, distribution, and reproduction in any medium, provided the original work is properly cited.

\begin{abstract}
In order to investigate the oil projected by gears rotating in an oil bath, a test rig has been set up in which the quantity of lubricant splashed at several locations on the casing walls can be measured. An oblong-shaped window of variable size is connected to a tank for flow measurements, and the system can be placed at several locations. A series of formulae have been deduced using dimensional analysis which can predict the lubricant flow rate generated by one spur gear or one disk at various places on the casing. These results have been experimentally validated over a wide range of operating conditions (rotational speed, geometry, immersion depth, etc.).
\end{abstract}

\section{Introduction}

Splash lubrication is traditionally used in low- to mediumspeed enclosed gears such as automotive gearboxes in which the lubricant is projected by the rotation of the gears. The main disadvantages are (i) the generation of significant power losses by churning and (ii) the absence of precise control in terms of lubricant supply. Based on a number of studies [1-10], there is general agreement on the fact that losses increase with rotational speed and immersion depth. Although lubricant churning can be considered as a major source of power loss in gearboxes, splash lubrication also contributes to the regulation of gear bulk temperature since some heat is removed from the tooth faces by centrifugal fling-off as demonstrated by Blok [11]. Using a general thermal model of an automotive manual gearbox, Changenet et al. [12] have confirmed the influence of the heat exchanges between the oil sump and several rotating elements on the global thermal behaviour and emphasized, in particular, the role of the immersion depth. Höhn et al. [13] have conducted a number of experiments showing that lowering the oil level in the sump reduces churning losses but also leads to higher gear bulk temperatures. These results have been theoretically confirmed by Durand de Gevigney et al. [14].
From the above-mentioned studies, it seems possible to define an optimal lubricant level in the sump in order to reduce churning losses and, from a thermal viewpoint, ensure satisfactory gear-lubricant heat exchanges. However, as far as the authors know, the influence of the oil level on the lubricant circulation and flow has received scant attention in the open literature despite the practical importance of ensuring sufficient lubrication and cooling of sensitive elements such as bearings. Because of its intrinsically chaotic nature, splash lubrication properties are hardly predictable and a lot of the development for this lubrication technique relies on a trial-and-error approach. In automotive applications, for example, casings with transparent walls are frequently employed in order to try to visualize the oil flow for a variety of operating conditions (rotational speeds, engaged gears, etc.). Such empirical methods are expensive and cannot be used at the early stages of design thus emphasizing the interest of studies aimed at predicting the volumes and spatial distributions of projected lubricant in a gearbox. In this paper, a methodology is proposed which makes it possible to estimate the amount of lubricant projected at several positions on the casing. To this end, a specific test rig has been exploited, and some general formulae are presented based on dimensional analysis. 


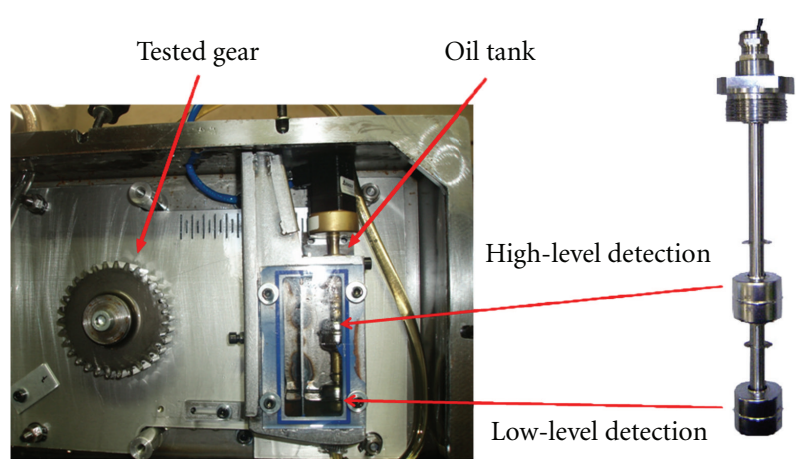

FIgURE 1: Oil tank in churning test rig.

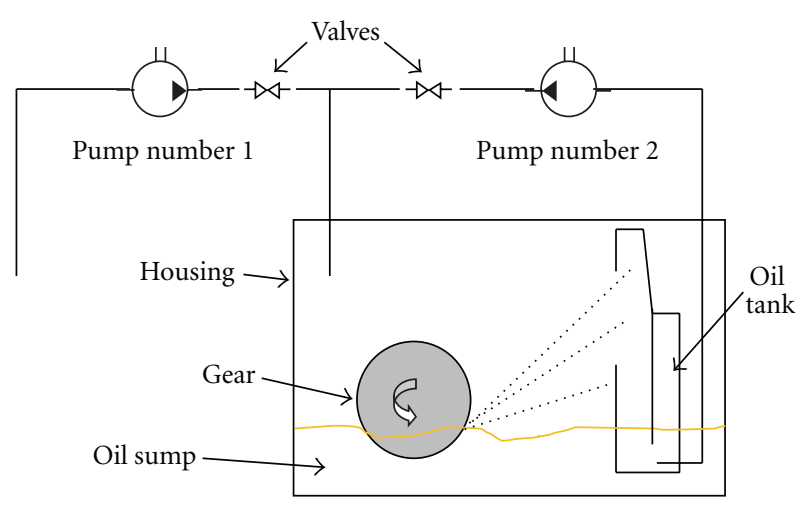

FIgURe 2: Hydraulic circuit.

\section{Test Rig}

The test rig developed to study churning losses and described in [7] has been modified in order to measure the oil flow rates projected on the casing walls. The pinion shaft is operated by an electric motor via a belt multiplying the rotational speed up to $7150 \mathrm{rpm}$. One of the faces of the oil sump is made of Plexiglas, and a tank has been placed in the housing to catch a part of the oil projected by the gear teeth due to centrifugal fling-off. To this end, an oblong-shaped window was drilled in the tank, and a level sensor is used to measure the time needed to fill a given volume (192 mL here) (Figure 1). In order to avoid the measurement uncertainties possibly induced by the more or less turbulent flows in the tank, a dividing wall has been introduced to separate the entry area from the measurement area in which the lubricant is far less agitated and levels can actually be read.

The hydraulic circuit in Figure 2 simultaneously enables the housing to be filled with oil and the tank to be drained when the sensor reaches the high-level detection threshold. Since measurements have to be carried out at a constant gear immersion depth, the oil in the tank is pumped and then injected into the casing (pump number 2). Finally, pump number 1 is used to fill the reservoir with lubricant at a set level.

The oil tank positioning is defined in Figure 3. Length $L$ corresponds to the distance between the gear axis of rotation and the tank which can be varied up to a maximum of

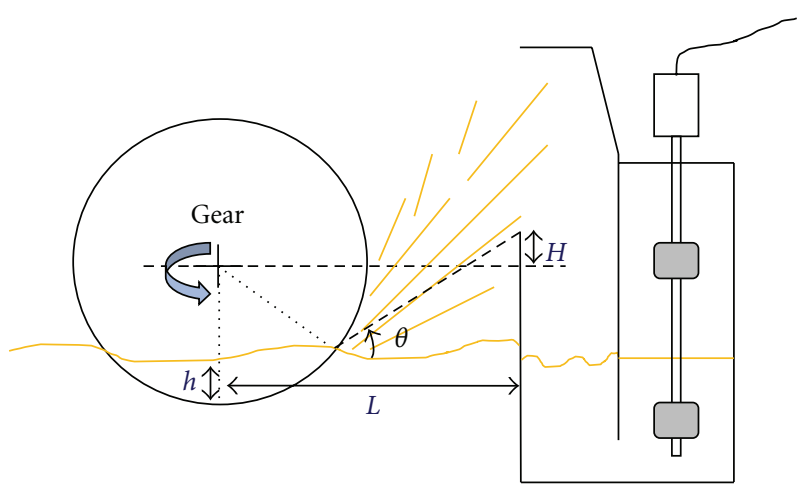

FIgURE 3: Definition of oil tank location.

$130 \mathrm{~mm} . H$ is the height of the window from the axis of rotation which can be changed between 0 and $115 \mathrm{~mm}$ (the latter corresponding to the case of a completely obstructed window). The width of the window is equal to $40 \mathrm{~mm}$ and the rotating gear is axially centred with respect to the tank.

The results presented in this paper are limited to the disks and spur gears defined in Table 1. Experiments were conducted with two different fluids: water and a mineral oil ( $v$ at $40^{\circ} \mathrm{C}=45.11 \mathrm{Cst}-\nu$ at $100^{\circ} \mathrm{C}=7.75 \mathrm{Cst}-\rho$ at $21^{\circ} \mathrm{C}=$ $\left.885 \mathrm{~kg} / \mathrm{m}^{3}\right)$.

\section{Validity of the Measurements}

Splash lubrication generates free surface flows characterised by wave trains created by the gear rotation which travel at certain speeds at the lubricant-air interface typical of transient flows. In such conditions, the number of data measurements has to be assessed in order to define a reliable experimental procedure. A number of measurements were performed for a range of operating conditions (gear geometry, rotational speed, tank location etc.) and various data acquisitions. Figure 4 presents some typical results using gear 1 partly immersed (relative immersion $=h / R_{p}=0.3$ ) at $1500 \mathrm{rpm}$ and for a tank location defined such that $H=10 \mathrm{~mm}$ and $L=110 \mathrm{~mm}$. Any individual acquisition corresponds to the complete cycle for filling and emptying the tank. It can be observed that, as the number of acquisitions increases, temperature increases too because of the power losses by churning which, in turn, influence the quantity of projected lubricant by centrifugal fling-off. In order to eliminate this influence in the analysis, all the results presented in this paper correspond to measurements based on 50 data acquisitions.

In order to analyse the reliability of the test machine, measurements were performed at various rotational speeds. Table 2 presents three series of tests carried out with gear 1 for the following tank location: $H=20 \mathrm{~mm}$ and $L=105 \mathrm{~mm}$. The results show that the maximum relative deviation in flow rate is about $8 \%$ which, considering the whole range of tests, corresponds to an average standard deviation of $4.9 \mathrm{~mL} / \mathrm{s}$. Compared with the nominal flow rates which generally lie between 50 and $200 \mathrm{~mL} / \mathrm{s}$, the standard deviation is considered as sufficiently small and the experimental results as acceptable. Finally, the uncertainty on 
TABLE 1: Gear and disk data.

\begin{tabular}{lcccccc}
\hline & Gear 1 & Gear 2 & Gear 3 & Gear 4 & Disk 1 & Disk 2 \\
\hline Module $(\mathrm{mm})$ & 1.5 & 3 & 5 & 3 & $/$ & $/$ \\
Number of teeth & 102 & 53 & 30 & 30 & $/$ & $/$ \\
Face width $(\mathrm{mm})$ & 14 & 24 & 24 & 24 & 25 & 1 \\
Outside diameter $(\mathrm{mm})$ & 156 & 165 & 165 & 96 & 161 & 160 \\
\hline
\end{tabular}

TABLE 2: Reliability of measurements.

\begin{tabular}{lccccc}
\hline$N(\mathrm{rpm})$ & \multicolumn{4}{c}{ Flow rate $(\mathrm{mL} / \mathrm{s})$} & \\
& Test 1 & Test 2 & Test 3 & Mean value & Standard deviation \\
\hline 500 & 174 & 168 & 166 & 169.3 & 4.16 \\
1000 & 119 & 118 & 119 & 118.7 & 0.58 \\
2000 & 86 & 88 & 93 & 89 & 3.61 \\
3000 & 79 & 80 & 81 & 80 & 1.00 \\
\hline
\end{tabular}

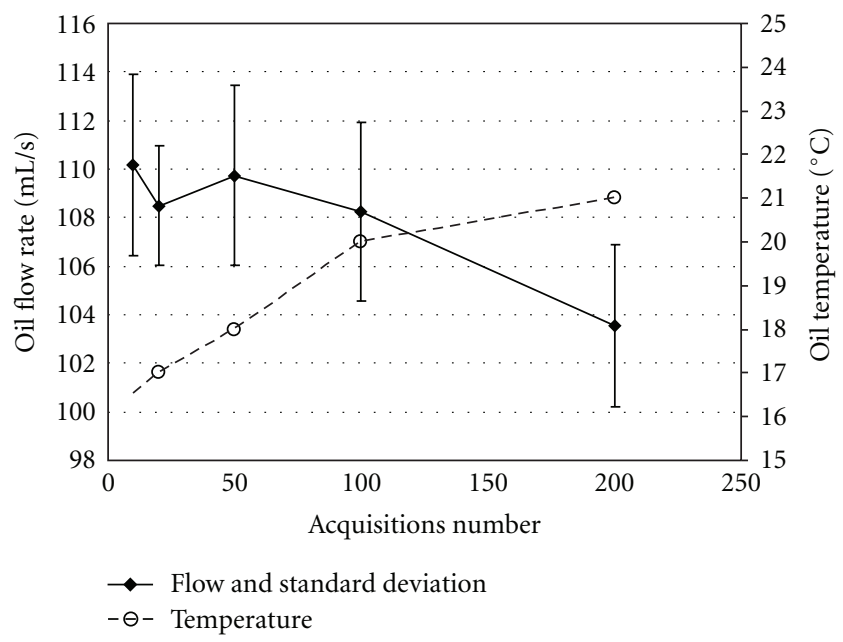

FIGURE 4: Influence of the number of acquisitions on flow rate measurement.

the volume measured by the two sensors was found to be around $2 \mathrm{~mL}$ leading to an error of $1 \%$.

\section{Experimental Results}

Figure 5 shows the flow rate evolutions versus rotational speed obtained for gear 2 with a relative immersion depth of 0.25 and three different tank locations characterised by $L=130 \mathrm{~mm}$ and $H$ between 10 and $30 \mathrm{~mm}$.

As expected, Figure 5 shows that the flow rate received depends on the position on the wall and it can be noticed that a pinion rotating partly in oil does not behave as a gear pump since the flow rate does not vary linearly with the rotational speed. The curves in Figure 5 also reveal the existence of two flow regimes with a transition around $1500 \mathrm{rpm}$, above which the flow rate is nearly constant with speed (constant depending on geometry) whereas, at lower speeds, the flow decreases as speed increases. These results can be explained as follows:

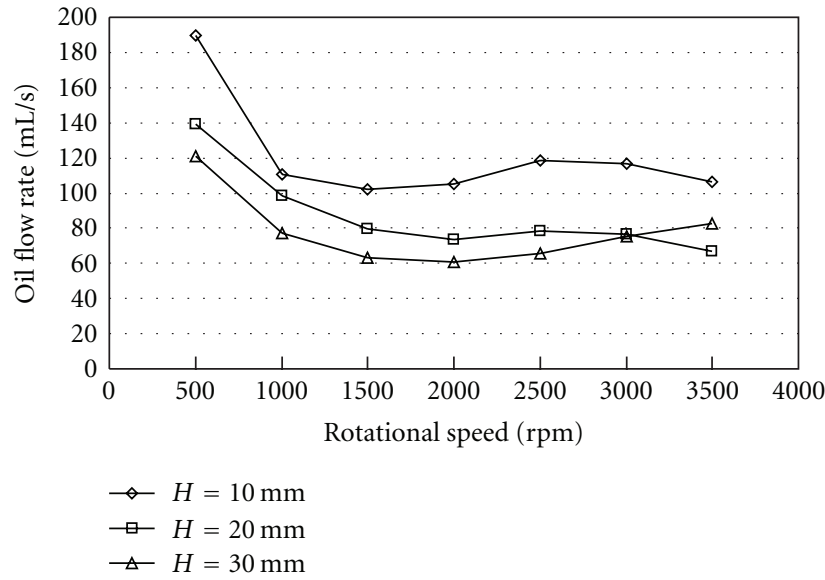

Figure 5: Typical evolutions of oil flow rates.

(i) At low rotational speeds, near $500 \mathrm{rpm}$, a significant amount of lubricant is located at the gear periphery and moves with it so that large quantities of lubricant can be expelled and reach certain places on the walls if they are sufficiently close to the gear.

(ii) At higher rotational speeds, centrifugal forces become predominant, no bulk fluid motion occurs but the lubricant is sprayed in a large cone and only a fraction of it can reach the aperture of the measuring device.

(iii) It has also to be noticed that, below $300 \mathrm{rpm}$, no lubricant can enter the tank whereas, between 300 and $500 \mathrm{rpm}$, the intertooth spaces are filled with oil and the flow rate increases with speed.

These observations have been confirmed with other geometries. For example, Figure 6 shows the flow rate evolutions versus rotational speed obtained for disk 1 with a relative immersion depth of 0.25 and two different tank locations characterised by $L=130 \mathrm{~mm}$ and $H$ between 20 and $40 \mathrm{~mm}$. The results in this figure confirm the presence of a transition point around $1500 \mathrm{rpm}$, above which the oil flow 


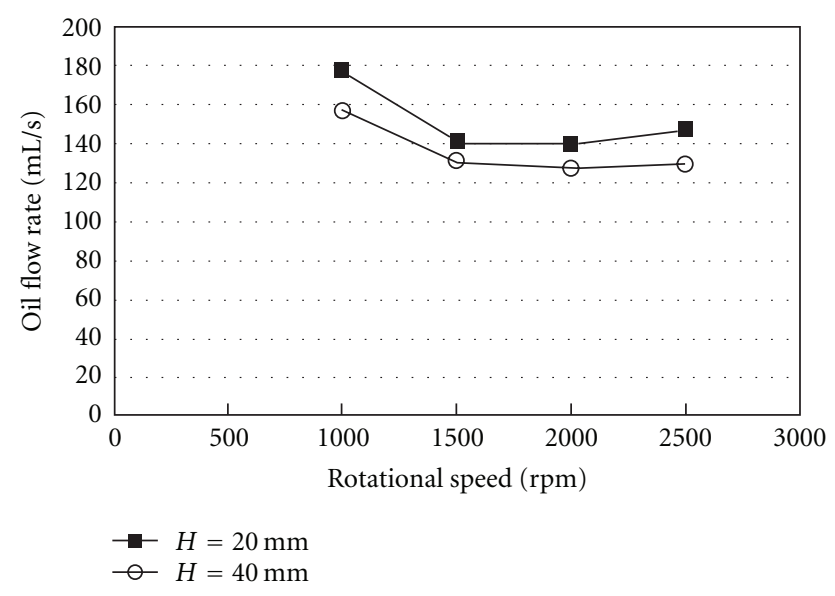

FIgURE 6: oil flow rates with a disk.

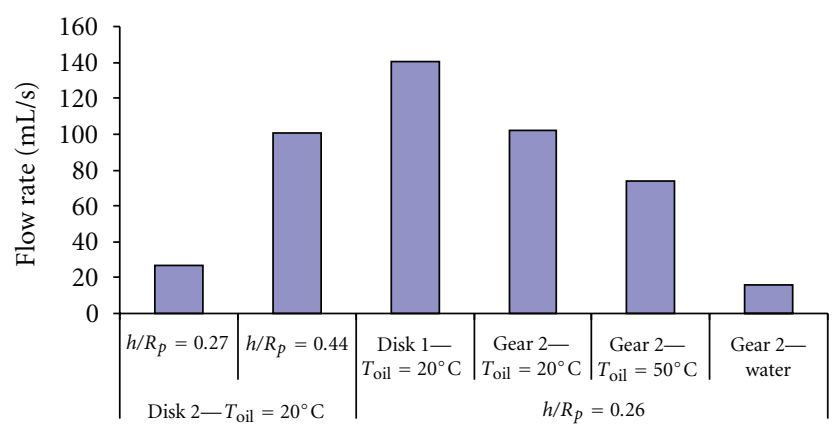

FIgURE 7: Influential parameters on flow rate.

rate becomes nearly constant versus speed. Experiments were also performed at $6000 \mathrm{rpm}$ in order to verify that this result remains the same at higher rotational speeds.

In order to identify the relevant parameters with regard to the volume of oil projected by a rotating pinion on the casing walls, some specific tests have been performed at $1500 \mathrm{rpm}$ for a given tank location $(L=130 \mathrm{~mm}$ and $H=$ $10 \mathrm{~mm}$ ) using disks and gears. The results are synthesised in Figure 7 from which the following conclusions have been drawn:

(i) The amount of lubricant received at one given location increases with the immersion depth.

(ii) Even disks of small face-width can generate significant flow rates suggesting that both the peripheral surface and the flanks contribute.

(iii) For equivalent geometrical parameters (radius, face width), a disk and a gear generate similar flow rates from which, it can be concluded that flow rates are largely independent of the parameters related to gear geometry, such as the module or the number of teeth.

(iv) For a given operating condition, flow rates are reduced by increasing the oil temperature or alternatively replacing oil by water suggesting that the fluid physical properties, and more specifically its viscosity, are influential.

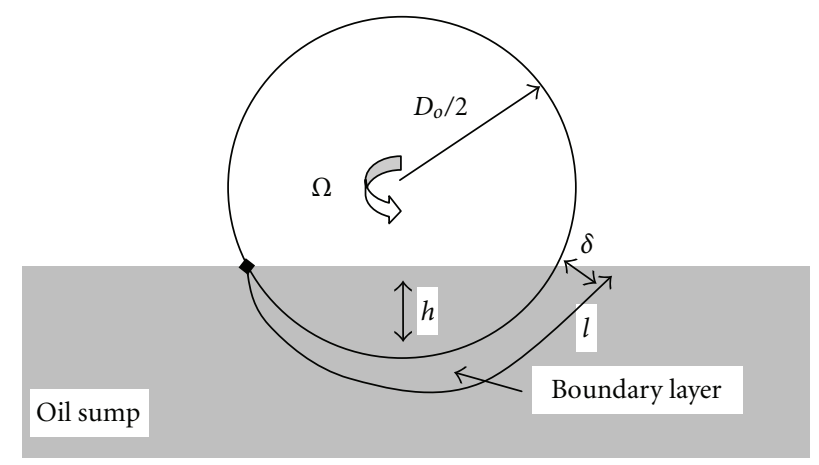

FIGURE 8: Schematic representation of the boundary layer on the side of a rotating disk.

Based on the conclusions above, it can be confirmed that the mechanism of oil projection differs from that in gear pumps. In this context, it seems interesting to investigate the hypothesis of a boundary-layer developing throughout the submerged part of a rotating disk and expelled by centrifugal forces. Theoretical flow rates can be deduced from this model and compared with the experimental evidence in order to assess the validity of this approach. Considering Figure 8, the leading edge is supposed to be located at the entry in the sump and boundary layers simultaneously develop on the two flanks and the side of the disc.

The length $l$ of the boundary-layer on the peripheral surface of the disk depends on its outer radius and its immersion depth as:

$$
l=D_{o} A \cos \left(\frac{D_{o} / 2-h}{D_{o} / 2}\right)
$$

Using the classic assumptions for laminar flows over flat plates, the hydrodynamic-boundary-layer thickness $\delta$ is found to be proportional to the disk arc length and the associated Reynolds number, such that

$$
\delta \cong \frac{l}{\sqrt{\mathrm{Re}_{l}}} .
$$

Since the flow velocity can be related to the peripheral speed of the rotating disk, an approximate order of magnitude of the flow rate generated by the side is

$$
q_{\text {side }} \cong \sqrt{\frac{b^{2} \nu \Omega D_{o}^{2}}{2} A \cos \left(\frac{D_{o}-2 h}{D_{o}}\right)} .
$$

As noted before, the flanks of a rotating disk can substantially contribute to the total flow rate. Using a similar approach for every elemental slice of width $d r$, located at a radius $r$, and integrating the associated elemental flow over the total immersed surface, the flow rate associated with the immersed flanks can be expressed as

$$
q_{\mathrm{fl}} \cong \sqrt{8 \Omega v} \int_{D_{o} / 2-h}^{D_{o} / 2} \sqrt{A \cos \left(\frac{D_{o} / 2-h}{r}\right)} r \cdot d r .
$$

The total flow rate expelled by the disk is obtained by adding the results of (3) and (4). Based on this approach, 


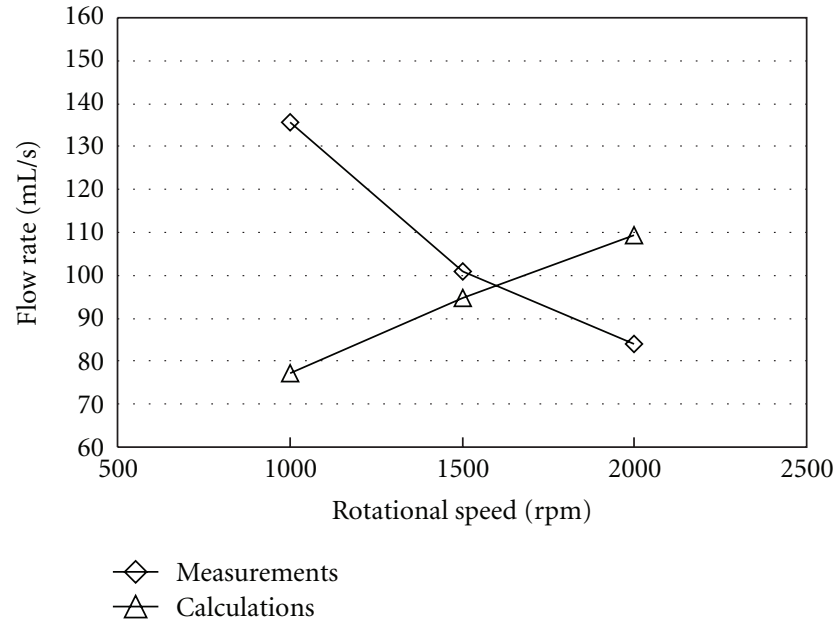

FIGURE 9: Comparison between experimental and numerical results by using boundary-layer theory.

the reduction in boundary-layer thickness could explain why flow rates are reduced for lower viscosities. A comparison between the corresponding calculated values and the results from the test rig is displayed in Figure 9 for the following operating conditions: disk 2 running partly immersed in mineral oil $\left(T_{\text {oil }}=20^{\circ} \mathrm{C}\right)$ with a relative immersion depth equal to 0.44 and a tank location defined by $L=130 \mathrm{~mm}$ and $H=10 \mathrm{~mm}$. This figure clearly shows that (3) and (4) do not correctly reproduce the experimentally found variations versus speed. The actual projection mechanisms are certainly more complex than the proposed simplified approach and further studies are needed.

\section{Dimensional Analysis}

In an attempt to propose empirical equations valid over a range of geometry and operating conditions, dimensional analysis is used by assuming that the most influential parameters are:

(i) The geometrical parameters associated with the gear or disk: $D_{o}, b$, and $h$.

(ii) The geometrical parameters associated with the tank location: $L$ and $H$.

(iii) The fluid parameters: $\rho, \mu$ and $\sigma$.

(iv) The dynamic parameters: $\Omega$ and $g$.

The oil flow rate $q$ can therefore be sought as a function of these parameters above, that is:

$$
q=f\left(D_{o}, b, h, L, H, \rho, \mu, \sigma, \Omega, g\right) .
$$

As noticed in the previous section, parameters such as the module or tooth number have a negligible influence and can consequently be discarded. The remaining geometrical parameters $D_{o}, h, L$, and $H$ can be associated to form a single group of parameters defined by

$$
\operatorname{tg}(\theta)=\frac{D_{o} / 2-h+H}{L-\left(D_{o} / 2 \sin \left(A \cos \left(1-2 h / D_{o}\right)\right)\right)},
$$

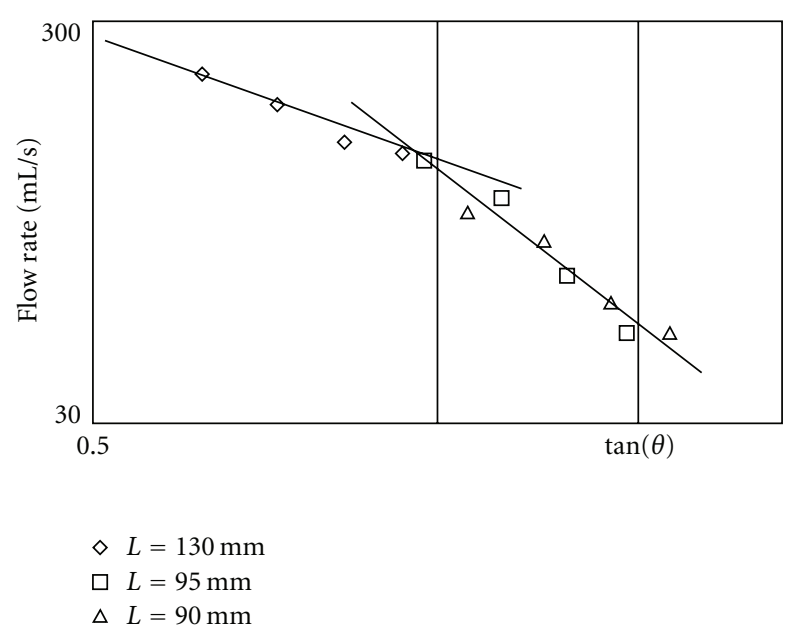

FIgURe 10: Oil flow rate versus angle $\theta$.

where $\operatorname{tg}(\theta)$ represents the minimum initial slope of the fluid path (Figure 3 ) ensuring that the liquid projected by the rotating gear/disk can pass through the oblong-shaped window of the measuring device (Figure 3 ).

Figure 10 reveals a 2-slope linear relationship between the measured oil flow rates and $\operatorname{tg}(\theta)$. These measurements were performed by using gear 4 with a relative immersion depth of 0.33 and different tank locations: $L$ varies from 90 to $130 \mathrm{~mm}$ and $H$ from 30 to $60 \mathrm{~mm}$. It is to be noted that similar results have been obtained for other operating conditions.

From the above remark it is deduced that parameters $D_{o}, h, L$, and $H$ are not independent, then (5) has to be transformed as follows:

$$
q=f\left(D_{o}, b, \theta, \rho, \mu, \sigma, \Omega, g\right) .
$$

Using the results from the boundary layer approach, a dimensionless flow rate is defined by using (3) and (4), that is, the contributions from the flanks and side of a rotating element as:

$$
\bar{q}=\frac{q}{q_{\mathrm{fl}}+q_{\mathrm{side}}} .
$$

The three fundamental parameters $D_{o}, \Omega$, and $\mu$ representing length, time, and mass are used to normalize all the other factors and, according to the theorem of Vaschy-Buckingham in dimensional analysis [15], $\bar{q}$ is found to depend on five groups of parameters as follows:

$$
\bar{q}=\psi_{1}\left(\frac{b}{D_{o}}\right)^{\psi_{2}} \operatorname{tg}(\theta)^{\psi_{3}} \operatorname{Re}^{\psi_{4}} \mathrm{We}^{\psi_{5}} \mathrm{Fr}^{\psi_{6}}
$$

where $\psi_{1} \cdots \psi_{6}$ are constant coefficients to be adjusted from experimental results.

The influence of the Reynolds number Re can be identified from tests with a lubricant at several temperatures $\left(20\right.$ and $50^{\circ} \mathrm{C}$ ) while all the other parameters (geometry, rotational speed, etc.) remain constant. $\psi_{4}$ can therefore be 
deduced from any pair of experimental results labelled $a$ and $b$, respectively, under the form:

$$
\psi_{4}=\frac{\ln \left(\overline{q_{a}} / \overline{q_{b}}\right)}{\ln \left(\operatorname{Re}_{a} / \operatorname{Re}_{b}\right)} .
$$

From the experimental evidence, a value of approximately 0.17 has been found for exponent $\psi_{4}$.

Tests with the pinion running partly immersed in water have been used in order to quantify the exponent of the Weber number leading to

$$
\psi_{5}=\frac{\ln \left(\overline{q_{a}} / \overline{q_{b}}\left(\mathrm{Re}_{b} / \mathrm{Re}_{a}\right)^{0.17}\right)}{\ln \left(\mathrm{We}_{a} / \mathrm{We}_{b}\right)} .
$$

The experimental results show that $\psi_{5}$ is almost equal to 0 or, in other words, that surface tension is not influential and can be discarded in the dimensional analysis.

A number of complementary tests were conducted in which (a) only the rotational speed is varied and, (b) only the geometrical characteristics: $\operatorname{tg}(\theta)$ or face width are changed in order to successively determine the remaining exponents:

$$
\begin{gathered}
\psi_{6}=\frac{\ln \left(\overline{q_{a}} / \overline{q_{b}}\left(\operatorname{Re}_{b} / \operatorname{Re}_{a}\right)^{0.17}\right)}{\ln \left(\mathrm{Fr}_{a} / \mathrm{Fr}_{b}\right)}, \\
\psi_{3}=\frac{\ln \left(\overline{q_{a}} / \overline{q_{b}}\left(\operatorname{Re}_{b} / \operatorname{Re}_{a}\right)^{0.17}\left(\mathrm{Fr}_{b} / \mathrm{Fr}_{a}\right)^{\psi_{6}}\right)}{\ln \left(\operatorname{tg}(\theta)_{a} / \operatorname{tg}(\theta)_{b}\right)} .
\end{gathered}
$$

Additionally, the experimental results show that $\psi_{2}$ is almost equal to 0 . The final relationships are synthesised below: If $\operatorname{tg}(\theta)>0.88$

(i) For $500<N<1500 \mathrm{rpm}$

$$
\bar{q}=0.31 \operatorname{tg}(\theta)^{-1.5} \operatorname{Re}^{0.17} \mathrm{Fr}^{-0.6} .
$$

(ii) For $N>1500 \mathrm{rpm}$

$$
\bar{q}=0.09 \operatorname{tg}(\theta)^{-1.5} \operatorname{Re}^{0.17} \mathrm{Fr}^{-0.3} .
$$

If $\operatorname{tg}(\theta)<0.88$

(i) For $500<N<1500 \mathrm{rpm}$

$$
\bar{q}=0.78 \operatorname{tg}(\theta)^{-1} \operatorname{Re}^{0.17} \mathrm{Fr}^{-0.6}
$$

(ii) For $N>1500 \mathrm{rpm}$

$$
\bar{q}=0.17 \operatorname{tg}(\theta)^{-1} \operatorname{Re}^{0.17} \mathrm{Fr}^{-0.3} .
$$

For rotational speeds below $300 \mathrm{rpm}$, the dimensionless flow rate is equal to zero. In the transition zone $(300<N<$ $500 \mathrm{rpm}$ ) a linear interpolation between this value and (13) or (15) is employed.

A typical series of comparisons between the experimental and the numerical results from (13) to (16) are displayed in Figure 11 where dimensionless flow rates are plotted against rotational speed for gear 1 and different locations of the oil tank. In this figure, the dotted lines represent

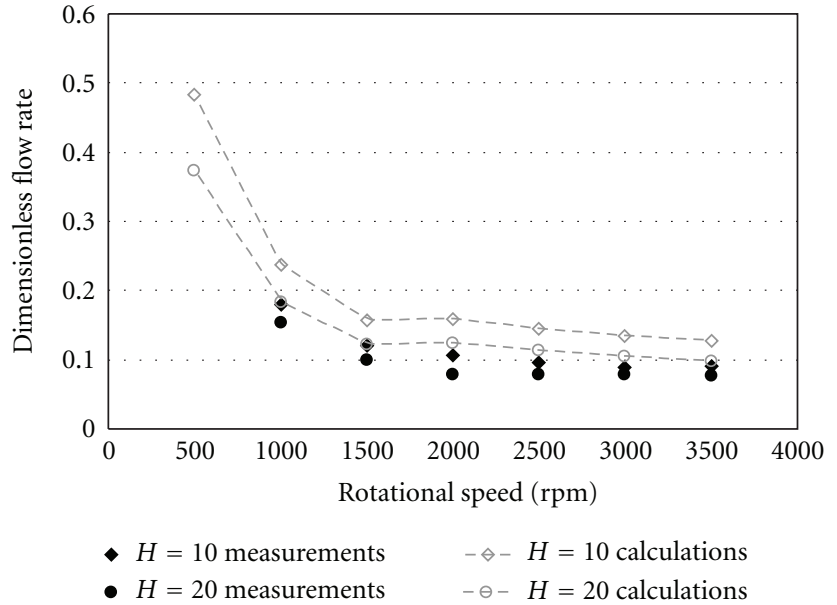

FIGURE 11: Comparison between experimental and numerical results [gear $1-T_{\mathrm{oil}}=20^{\circ} \mathrm{C}-h / R_{p}=0.36-L=130 \mathrm{~mm}$ ].

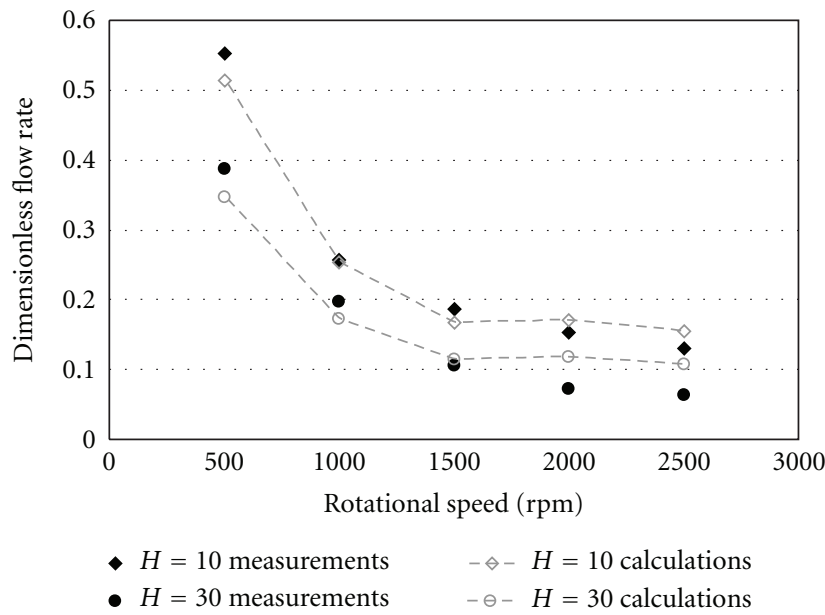

Figure 12: Comparison between experimental and numerical results [gear $2-T_{\text {oil }}=50^{\circ} \mathrm{C}-h / R_{p}=0.25-L=130 \mathrm{~mm}$ ].

the numerical results. The results show that the flow rate predictions are satisfactory with a larger discrepancy at the lowest rotational speeds (average error of 11\%). More than 250 tests were carried out and the maximum deviation between the numerical and experimental flow rate was found to be equal to $15 \%$. For the sake of illustration, additional curves are given in Figure 12 for different geometries and operating conditions which prove the versatility of the proposed formulae.

\section{Conclusion}

A test rig had been modified in order to quantify the amount of lubricant splashed at various locations on the casing walls by the rotation of a pinion partly immersed in oil. Based on a number of experimental results, a set of analytical formulae has been established using dimensional analysis in relation to an approximate theoretical approach relying on the concept 
of boundary layer. More than 250 different configurations have been tested and the agreement between the predictions and the experimental evidence is good. It is believed that these results can be useful at the early design stage and help understand splash lubrication characteristics particularly in automotive applications.

From a practical viewpoint, it has been demonstrated that a disk and a gear with similar geometry (outer radius and face width) generate equivalent flow rates. This conclusion is important for automotive applications as it underlines that synchronizers can also contribute to gearbox lubrication. The role of the physical properties of the lubricant is emphasized and viscosity appears as highly influential since it has been found that flow rates decrease with the operating viscosity. However, further experiments with different types of lubricants (mineral and synthetic oils) are certainly needed in order to confirm these findings or not. Experiments in this paper were limited to individual disks and spur gears; further investigations are certainly needed concerning the contribution of pinion-gear pairs along with that of helical teeth.

\section{Nomenclature}

$b: \quad$ Face width $[\mathrm{m}]$

$D_{o}$ : Outside diameter $[\mathrm{m}]$

Fr: Froude number

$g:$ Acceleration of gravity $\left[\mathrm{m} / \mathrm{s}^{2}\right]$

$H$ : Height $[\mathrm{m}]$

$h$ : Immersion depth of a pinion $[\mathrm{m}]$

L: $\quad$ Length $[\mathrm{m}]$

$l$ : Characteristic length of the boundary-layer $[\mathrm{m}]$

$m$ : Module [m]

$N$ : Rotational speed [rpm]

$q$ : Fluid flow rate $\left[\mathrm{m}^{3} / \mathrm{s}\right]$

$\bar{q}$ : Dimensionless flow rate

Re: Reynolds number

$R_{p}:$ Pitch radius $[\mathrm{m}]$

$T$ : Fluid temperature $\left[{ }^{\circ} \mathrm{C}\right]$

We: Weber number

$\delta: \quad$ Thickness of the boundary-layer $[\mathrm{m}]$

$\theta: \quad$ Angle [rad]

$\mu$ : Dynamic viscosity [Pas $]$

$v$ : Kinematic viscosity $\left[\mathrm{m}^{2} / \mathrm{s}\right]$

$\rho: \quad$ Fluid density $\left[\mathrm{kg} / \mathrm{m}^{3}\right]$

$\sigma: \quad$ Surface tension $[\mathrm{N} / \mathrm{m}]$

$\Omega$ : Rotational speed $[\mathrm{rad} / \mathrm{s}]$.

\section{Acknowledgments}

The authors would like to gratefully thank PSA Peugeot Citroën and TOTAL for sponsoring this study. They also thank Vincent Ricol and Louis Bartolomé for their important contributions to the test rig design and construction.

\section{References}

[1] A. S. Terekhov, "Hydraulic losses in gearboxes with oil immersion," Vestnik Mashinostroeniya, vol. 55, no. 5, pp. 1317, 1975.
[2] E. Lauster and M. Boos, "Zum Wärmehaushalt mechanischer Schaltgetriebe für Nutzfahrzeuge," VDI-Berichte, vol. 488, pp. 45-55, 1983.

[3] R. J. Boness, "Churning losses of discs and gears running partially submerged in oil," in Proceedings of the International Power Transmission and Gearing Conference: New Technologies for Power Transmissions of the 90's, pp. 355-359, Design Engineering Division, ASME, Chicago, Ill, USA, April 1989.

[4] B. R. Höhn, K. Michaelis, and T. Völlmer, "Thermal rating of gear drives: balance between power loss and heat dissipation," American Gear Manufacturers Association Document, 96FTM8, p. 12, 1996.

[5] P. Luke and A. V. Olver, "A study of churning losses in dip-lubricated spur gears," Proceedings of the Institution of Mechanical Engineers G, vol. 213, no. 5, pp. 337-346, 1999.

[6] C. Changenet and P. Velex, "A model for the prediction of churning losses in geared transmissions-preliminary results," Journal of Mechanical Design, vol. 129, no. 1, pp. 128-133, 2007.

[7] C. Changenet and P. Velex, "Housing influence on churning losses in geared transmissions," Journal of Mechanical Design, vol. 130, no. 6, Article ID 062603, 6 pages, 2008.

[8] S. Seetharaman and A. Kahraman, "Load-independent spin power losses of a spur gear pair: model formulation," Journal of Tribology, vol. 131, no. 2, Article ID 022201, 11 pages, 2009.

[9] G. Leprince, C. Changenet, F. Ville, P. Velex, C. Dufau, and F. Jarnias, "Influence of aerated lubricants on gear churning losses-an engineering model," Tribology Transactions, vol. 54, no. 6, pp. 929-938, 2011.

[10] C. Changenet, G. Leprince, F. Ville, and P. Velex, "A note on flow regimes and churning loss modeling," Journal of Mechanical Design, vol. 133, no. 12, Article ID 121009, 5 pages, 2011.

[11] H. Blok, "Transmission de chaleur par projection centrifuge d'huile," Société d'Etudes de l'Industrie de l'Engrenage, vol. 59, pp. 14-23, 1970.

[12] C. Changenet, X. Oviedo-Marlot, and P. Velex, "Power loss predictions in geared transmissions using thermal networksapplications to a six-speed manual gearbox," Journal of Mechanical Design, vol. 128, no. 3, pp. 618-625, 2006.

[13] B. R. Höhn, K. Michaelis, and H. P. Otto, "Influence of immersion depth of dip lubricated gears on power loss, bulk temperature and scuffing load carrying capacity," International Journal of Mechanics and Materials in Design, vol. 4, no. 2, pp. 145-156, 2008.

[14] J. Durand de Gevigney, C. Changenet, F. Ville, and P. Velex, "Thermal modelling of a back-to-back gearbox test machine: application to the FZG test rig," Proceedings of the Institution of Mechanical Engineers J, vol. 266, no. 6, pp. 501-515, 2012.

[15] S. Candel, Mécaniques des Fluides-Cours, Dunod, Paris, France, 2nd edition, 1995. 

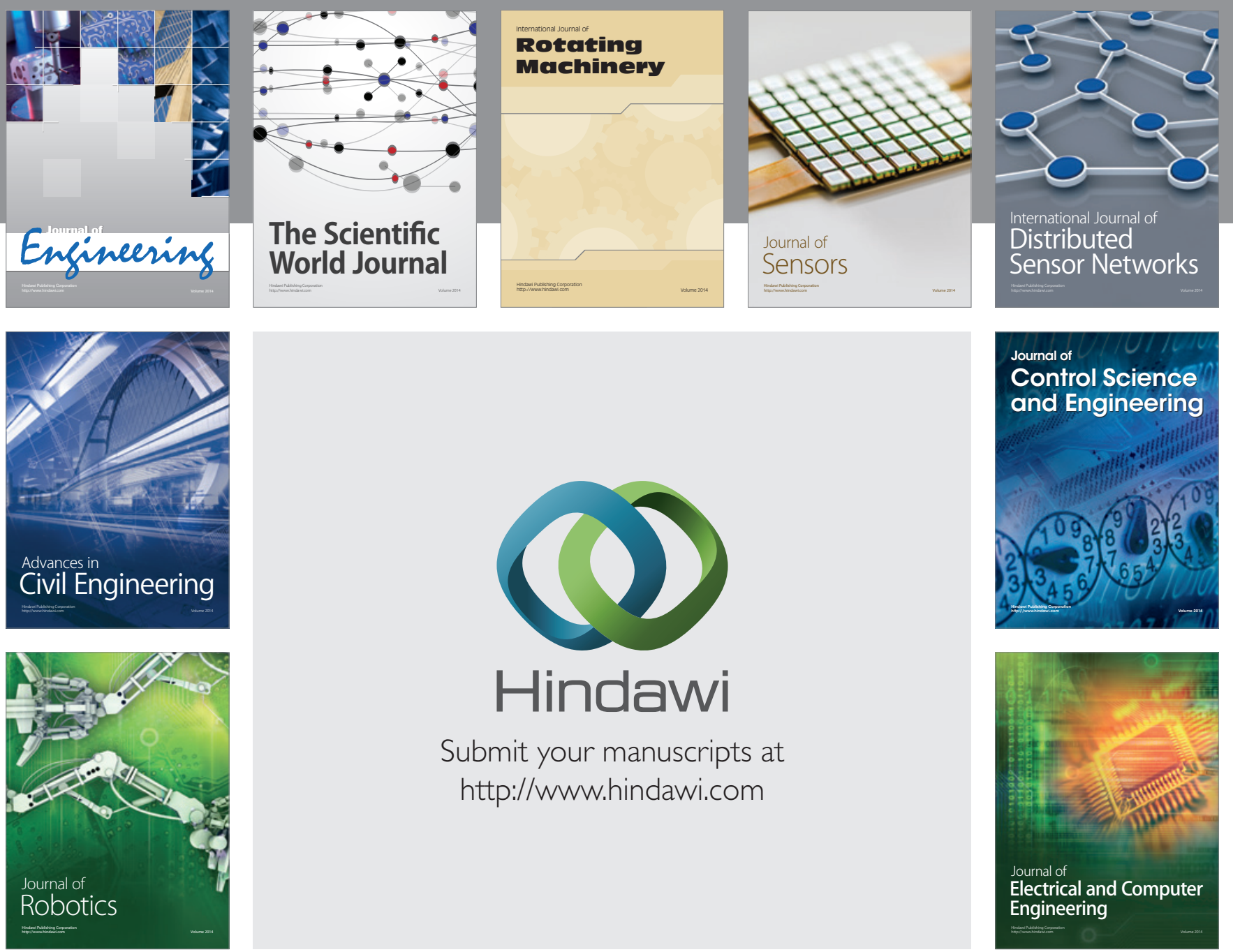

Submit your manuscripts at

http://www.hindawi.com
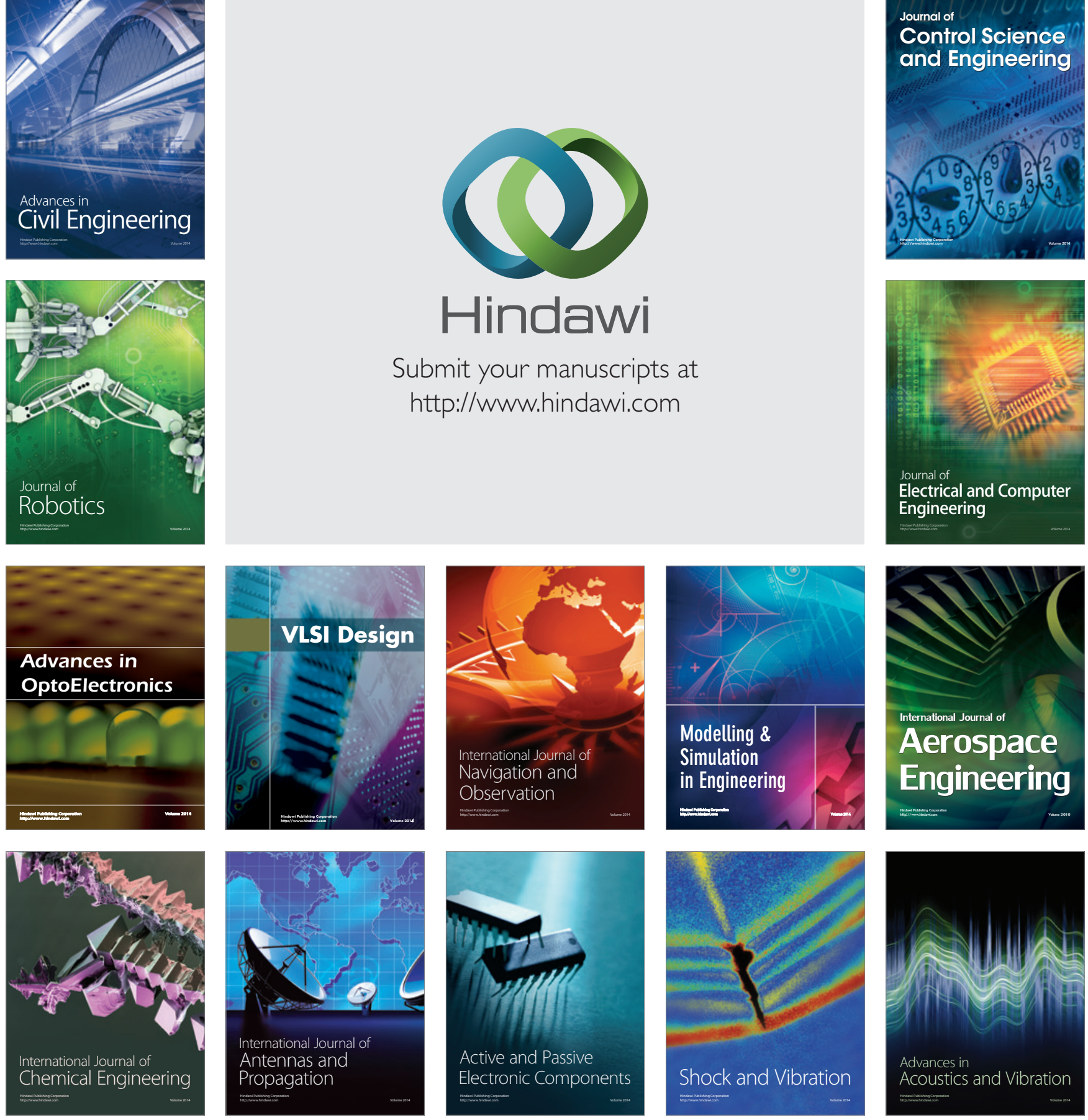